\title{
EXPERIMENTAL FACILITY IHEPNP FOR FUNDAMENTAL AND APPLIED RESEARHES IN ENERGY RANGE UP TO $100 \mathrm{MeV}$
}

\author{
V.B. Ganenko, V.I. Kasilov, G. D. Kovalenko, N. I. Maslov, I. L. Semisalov \\ National Science Center "Kharkiv Institute of Physics and Technology", 61108 Kharkiv, Ukraine
}

(Received July 20, 2020)

\begin{abstract}
The possibility of creating an experimental setup in building No.3 of the IHEPNP NNC KIPT (LUE-300 complex) on the basis of the existing LUE-60 electron accelerator and the existing experimental infrastructure is being discussed. It is planned to raise the energy of the electron beam to $100 \mathrm{MeV}$ and create two beam lines: one is for reaserches with intense beams of electrons and photons, including linearly polarized ones, and the other - for investigations with the low intensive beams of electrons and positrons. Implementation of the project will open opportunities for a wide range of research programs in the field of interaction of the radiation with amorphous and crystalline matter, nuclear physics and astrophysics, as well as in the applied research.
\end{abstract}

PACS: 03.65.Pm, 03.65.Ge, 61.80.Mk

\section{INTRODUCTION}

Fundamental and applied research has been carried out at KIPT since its foundation, and they were carried out both in the frontier areas of fundamental science of that time, such as nuclear physics, low temperature physics, etc., and also with the aim of solving complex technical problems, such as the atomic project of the Soviet Union [1]. Since the mid-60s of the last century, the basis for research has been the linear electron accelerators LUE-2000 and LUE-300, as well as the experimental infrastructure associated with them: experimental halls with magnetic spectrometers, various detecting systems with appropriate electronics, etc. The maximum beam energy of these accelerators was $1.8 \mathrm{GeV}$ and $260 \mathrm{MeV}$, respectively, which made it possible to carry out extensive research programs in nuclear physics and elementary particle physics in the region of intermediate energies, to study the phenomena arising at interaction of radiation with crystal structures, and also to carry out research in applied physics.

In the early 90s, the accelerators have been stopped and these studies have been discontinued. The lack of the necessary state funding of the scientific research in the following years did not allow the modernization of these facilities or to creation of new ones. The accelerators and the experimental infrastructure are morally and physically obsolete, and as a result, the institute does not currently have an experimental base for researches. The cessation of practical research work at the modern level led to the outflow of active scientists, on the one hand, and the lack of a real opportunity for the training of young specialists oriented to work at the institute on the other hand, and, in general, it brought to deceasing the staff qualification.

To overcome these negative trends, it is necessary to resume experimental studies at the institute as soon as possible. Due to the lack of necessary funding, at the first stage, the resumption of research is possible with the maximum use of the resources of the institute, of the existing experimental equipment and infrastructure, and of the scientic personnel. This circumstance imposes restrictions on the possible directions and level of research at the first stage. When the first stage will be successfully completed and the researches will be resumed, in the next stage it is necessary to start creating a new modern experimental base. In solving this future problem, the key issue is the training of necessary qualified personnel, which can be solved in the course of practical research work on the planned facility.

In this paper we discuss the possibilities of solving the first stage - the resumption of experimental researches in the fields traditional for the institute, in which we can still use the equipment that is currently available, and also gained extensive experience. As a possible variant it is proposed to create an experimental facility in the building No.3 (LUE-300 complex) on the basis of the available electron accelerator LUE-60, and the existing experimental infrastructure in there.

\section{CONCEPTUAL SCHEME OF THE FACILITY}

The present status of the LUE-300 complex is shown in Fig.1. It can be seen that, in principle, there are

*Corresponding author E-mail address: ganenko@kipt.kharkov.ua 
some experimental sites where experiments had being produced in the past, and some infrastructure for the research is still exists and can be upgraded and used at present. This is:

- hall of the $30 \mathrm{MeV}$ electron accelerator (LUE30) (the so-called, "Blue Output"). Possible and planned experiments in this hall are aimed on applied researches in the fields of nuclear physics, nuclear energetic, solid state physics, nuclear medicine, and on investigations of photo and electro-nuclear reactions in the range of Giant Dipole Resonance;

- hall of the X-ray generator N-100 ("Nestor"). The planned experiments are aimed on applied researches in the fields of solid state physics and medicine;

- hall of direct exit. Possible experiments, which had being performed in the past and can be renew, is related with studies of the interaction of electrons with single crystals, and applied researches in the field of nuclear energetic;

- hall of the spectrometer SP-95. Possible researches on this facility can be related with investigations of the nuclei structure by electron scattering method;
- hall in the building 3A (the so-called, "Streamer Chamber Hall"). Researches in this hall had being planned in the field of photodisintegration of the lightest nuclei with using the streamer chamber.

Due to dismantling of the LUE-300 accelerator, any experiments in the direct exit hall, the SP-95 spectrometer hall, and the streamer chamber hall became impossible. Therefore, the any work carried out in these halls was discontinued due to the lack of the beam and the real perspective for its obtaining in the future. Currently, the SP-95 spectrometer is mothballed, and the experimental hall is closed, work on the streamer chamber creation has also been discontinued.

At present, there is only one facility in operation - accelerator in the "Blue Output" hall. The accelerator produces an electron beam with maximal energy $E_{0}=30 \mathrm{MeV}$, the parameters of which naturally do not meet modern requirements, bacause it has been operating without any modernization or reconstruction more than a half of century. Low beam energy and practically lack of experimental infrastructure limit experimental possibilities. Therefore it is used mainly for applied research and the irradiation experiments.

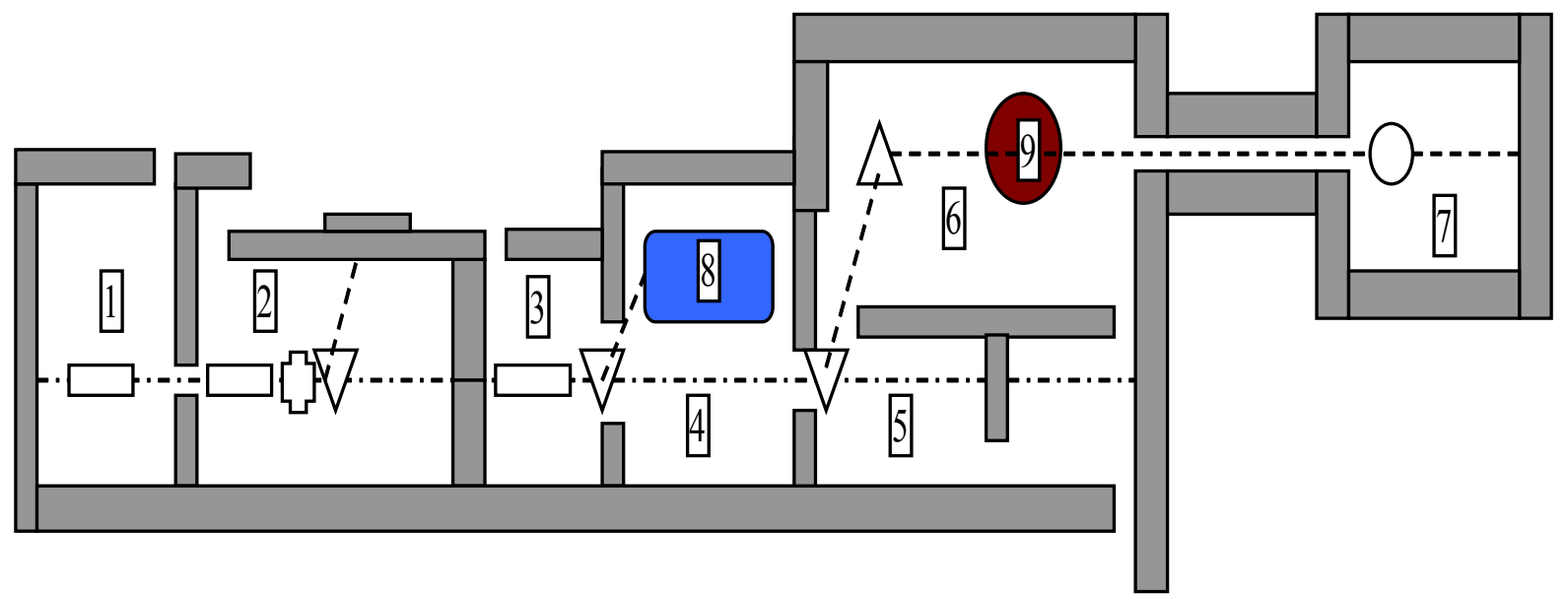

Fig.1. Present status of the LUE-300 accelerator complex: 1 - hall of the LUE-10 accelerator; 2 hall of the $30 \mathrm{MeV}$ electron accelerator (LUE-30); 3-injector of the N-100 facility; 4 - hall of the $X$-ray generator N-100 ("Nestor"); 5 - hall of direct exit; 6 - hall of the spectrometer SP-95; 7 hall of the streamer chamber; 8 - X-ray generator N-100 ("Nestor") storage ring; 9 - spectrometer SP-95

To renew experimental research, it is planned to upgrade the "Blue Output" facility. Modernization includes, firstly, increasing the energy of the electron beam to $E_{0} \sim 100 \mathrm{MeV}$, and improving its parameters (emittance, energy spread and divergence), and secondly, the creation of two beam lines to expand the experimental possibilities of the setup. One beam line will be aimed on experiments in the field of nuclear physics and astrophysics with intensive beams of electrons and photons, including linearly polarized, on studying interaction of electrons with crystals (including the thin ones), the other one is planned for experiments with beams of electrons and positrons of low intensity ( $\sim 1$ particle per accelerator pulse) aimed to study their interactions with crystals and nanostructures, to research of scintillation materials, detectors testing, etc.

\subsection{PRINCIPLE SCHEME OF THE FACILITY}

The facility is placed into three separate rooms, divided by the shielding walls: the room of the linear accelerator, the hall of the system of the electron beam formation and the experimental hall. 


\subsubsection{ACCELERATOR}

For the electron beam production, the LUE-60 accelerator will be used, which was designed to inject an electron beam into the N-100 storage ring. The accelerator will be placed in a separate room, which is located in front of the "Blue Output" experimental hall. Parameters of the electron beam, produced by the LUE-60 accelerator, have been determined dur- ing the commission work [2] and are presented in Table 1. It is expected, the accelerator will be able to produce the beam with energy up to $90 \mathrm{MeV}$, and the divergence sufficient for performing studies with the crystals. To increase the beam energy, it is planned to install additional section which will allow raising the beam energy to $100 \ldots 120 \mathrm{MeV}$ that will provide more opportunities for research.

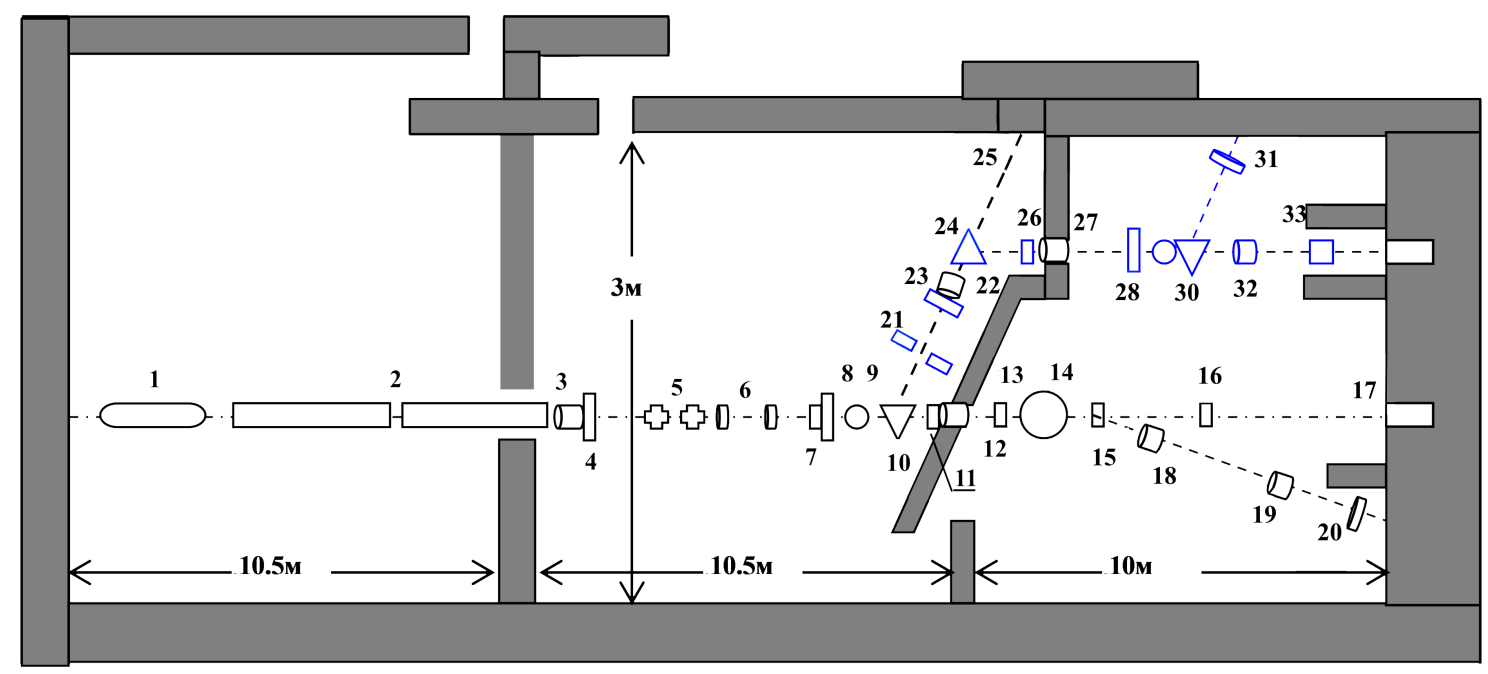

Fig.2. Sheme of the experimental set-up: 1 - injector; 2 - accelerating sections; 3 - collimator; 4 electron beam position and current monitor; 5 - quadrupole lenses; 6 - two pairs of beam correctors; 7secondary emission monitor; 8 - monitor of the electron beam position on the photon radiator (crystal); 9 - goniometer (or radiators for secondary particles production); 10 - the first bending magnet; 11 monitor of the photon beam position on the collimator; 12 - photon collimator; 13 - monitor of the photon beam position on the nuclear target; 14 - nuclear target and detecting equipment; 15 - photon scatterer; 16 - ionization chamber; 17 - quantometer (or Faraday cup); 18 and 19 - collimators of the Compton scattering channel; 20 - detector of the scattered photons; 21 - collimator-monochromator; 22, 26, 28 - monitors of the secondary particles beam position; 23 - collimator of secondary particles; 24 second bending magnet; 25 - cylinder Faraday; 27 - collimator; 29 - goniometer; 30 - cleaning magnet; 31 - detector of the secondary particles; 32 - photon collimator; 33 - photon detector

Table 1. Parameters of the LUE-60 accelerator

\begin{tabular}{|c|c|}
\hline Energy of an electron beam, $\mathrm{MeV}$ & $60 \ldots 90$ \\
\hline Current, $\mu A$ & up to 1 \\
\hline Frequency of packages, $\mathrm{Hz}$ & $1 \ldots 50$ \\
\hline Pulse Duration, $\mu \mathrm{s}$ & $\sim 1.4$ \\
\hline The width of the energy spectrum, $\%$ & 1.5 \\
\hline Emittans, mrad & 0.1 \\
\hline Beam sizes at the exit, $\mathrm{mm}$ & $\sim 5$ \\
\hline
\end{tabular}

\subsection{BEAM LINES}

The electron beam from the accelerator is directed to the system of the beam formation. The system consists of an electron collimator (3), quadrupole lenses (5) and two pairs of the beam correctors (6). The beam current and position at the exit from the accelerator are controlled by a transit-time monitor (4). The formation system directs the electron beam to the place, where a goniometer or target block for secondary particles production will be placed. The size of the beam, before these units, is controlled by a sensor (7), and the beam intensity by a secondary emission monitor (8). Then the beams are directed to the experimental hall by the beam lines No.1 or No.2.

Beam line No.1 (main) is designed to work with intensive beams of the electrons (up to $\sim 1 \mu A$ ) and photons. If a photon beam is used for experiment, the electron beam is directed to a photon radiator (9), amorphous or crystalline, located in the goniometer. After passing through the radiator, the electron beam is deflected by the magnet (10) and directs to the beam dump, where the Faraday cylinder (25) is located, which measures the current of the beam and absorbs it. In this case, the elements of the formation of low-intensity beams (21-23) are removed from the beam line, and the second bending magnet (24) is switched off.

The photon beam is cleaned of charged particles by the magnet (10) and is formed by a photon collimator (12) installed in front of the shielding wall at the entrance to the experimental hall. The position 
of the photon beam on the collimator is controlled by a position monitor (11). The distance from the photon target to the entrance to the collimator is $\sim 2 \mathrm{~m}$. Then, the photon beam is directed to a nuclear target (14). The position and size of the photon beam on the target is controlled by a position monitor (13). Due to large natural divergence of the photon beam, it is advisable to place the nuclear target closer to the shielding wall of the experimental hall. Minimal distance from the photon radiator to the target is about of $\sim 3 \mathrm{~m}$. The photon beam intensity is measured by a thin-walled ionization chamber (16). Then the beam is sent to the beam-dump, where a quantometer (17) is placed for measuring the total photon flux.

When working with a beam of linearly polarized photons, obtained due to process of the coherent bremsstrahlung of electrons in a diamond crystals, it is necessary to control spectrum of the photon beam and its stability during the experiment. Spectra measurements are planned to perform by the Compton scattering method. For this purpose, a scatterer (15) is placed on the beam line. The scaterred photons are selected under angle $\sim 5$ degrees by collimators (18 and 19). Spectrum of the scattered photons is registered by a $\mathrm{NaI}$ (or $\mathrm{CsI}$ ) detector located in a well-shielded place.

The collimator (12) determines the angle of the photon beam collimation and its size on the nuclear target. Expected size of the entrance hole of the collimator for the collimation angle $\theta_{c} \sim \theta_{\gamma}$ is $d \approx 34(20) \mathrm{mm}$ in diameter for the electron energy $E_{0}=60(100) \mathrm{MeV}$, respectively, and the pointlike electron beam. $\left(\theta_{\gamma}=m c^{2} / E_{0}\right.$ is the natural radiation angle, $m$ is the electron mass). In this case, the expected beam size on the nuclear target is $d \approx 51(30) \mathrm{mm}$. Accordingly, for the collimation angle $\theta c \sim 0.5 \theta_{\gamma}$, the diameter of the collimator hole is $d \approx 17(10) \mathrm{mm}$, and the beam size on the target is $d \approx 26(15) \mathrm{mm}$.

When working with an electron beam, the photon target (9) is removed, the bending magnet (10) is turned off, and the electron beam is directed into the experimental hall. After passing through the target, the beam is directed to the Faraday cylinder (17), which measures the current of an electron beam and absorbs it.

The beam line No.2 is aimed for the secondary beams of electrons and positrons, with an intensity of $\sim 1$ particle per pulse of the accelerator. The secondary particles (electrons and positrons) are generated at the interaction of an electron beam with a photon radiator (9) from tungsten, with a thickness of several radiation lengths. The resulting secondary particles are captured by the magnet (10) into the beam line, where the elements of the beam formation and control are located, including the system of the collimators $(21,23,27)$ and the beam position monitors $(22,26,28)$.

A magnet (24) directs the beam into the experimental hall through the input collimator (27) onto the goniometer (29). The secondary beam position on the collimator is controlled by the monitor (26), and its size and position in front of the crystal is controlled by the monitor (28). After passing through the target, the beam deflected by the magnet (30) and total number of the particles is registered by the detector (31). The produced gamma-quanta pass (if necessary) through a collimator (32) and are registered by the detector (33).

\section{EXPECTED PARAMETERS OF THE LINEAR POLARIZED PHOTON BEAM}

From analysis of the possible methods of the linearly polarized photon beam generation, the method, based on the process of coherent bremsstrahlung (CB) of electrons in a diamond crystal is most preferable in our conditions.

The expected spectra and polarization of the CB beam have been calculated using code [3]. The code takes into account parameters of the electron beam, multiple scattering of the electron beam in the crystal, collimation of the gamma radiation. The calculations have been produced for the electron beam energy $E_{0}=100 \mathrm{MeV}$, the diamond crystal of $0.1 \mathrm{~mm}$ thick, and orientation in which main contribution to the CB cross section gives one vector (022) of the reciprocal lattice. The other beam parameters, which were used for the computations are presented in Table 2. The CB peak energy was chosen to be $E_{\gamma, p}=18 \mathrm{MeV}$ that corresponds to the energy range of Giant Dipole Resonance. Results of the calculations are shown in Fig.3.

One can see that the $\mathrm{CB}$ intensity relatively to the intensity of incoherent part (Iin) of the radiation,

$$
\beta=\frac{I_{c o h}+I_{m}}{I_{m}}
$$

in the point of the $\mathrm{CB}$ maximum $\beta_{\max }$ ( $\beta_{\max }$ is the so-called, the enhancement or the coherent effect) increases from $\beta_{\max } \sim 1.3$ to $\sim 2.9$ with reducing the collimation angle from $\theta_{c}=\theta_{\gamma}$ to $\sim 0.3 \theta_{\gamma}$. Polarization of the $\mathrm{CB}$ in the maximum $P_{\gamma, \max }$ at these conditions is high enough and changes from $P_{\gamma, \text { max }} \sim 15 \%$ at $\theta_{c}=\theta_{\gamma}$ to $P_{\gamma, \max } \sim 50 \%$ at $\theta_{c}=0.3 \theta_{\gamma}$. Both coherent effect and polarization are decreased, when the coherent peak moves to higher energies. 

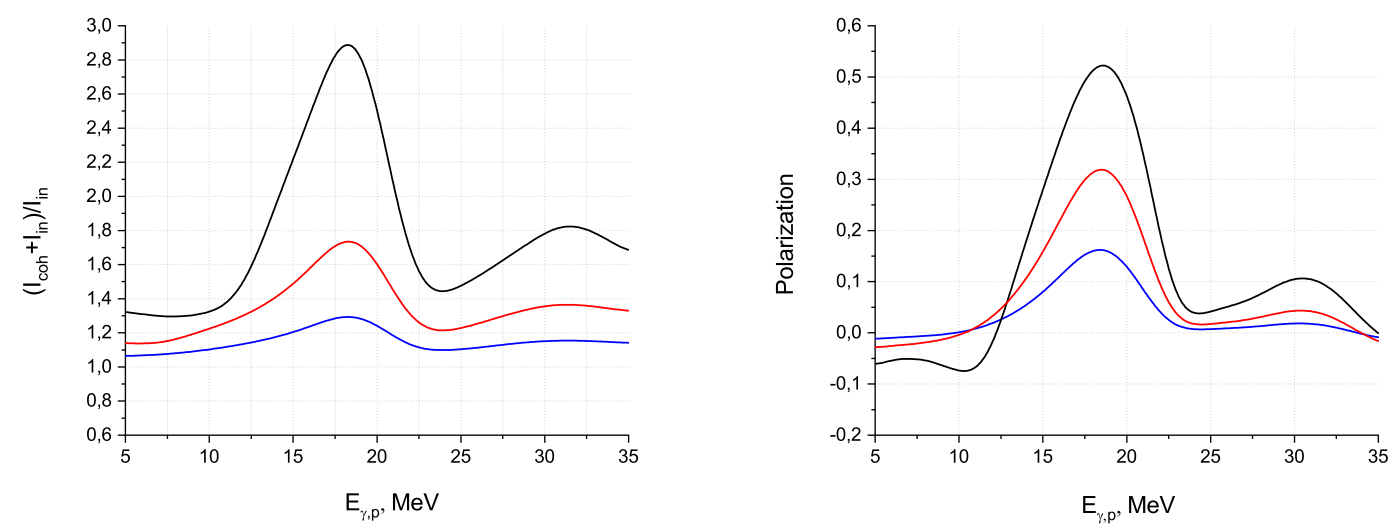

Fig.3. Relative intensity (left) and polarization (right) of the $C B$ of electrons with energy $E_{0}=100 \mathrm{MeV}$ in diamond crystal $0.1 \mathrm{~mm}$ thick at the $C B$ peak energy $E_{\gamma, p}=18 \mathrm{MeV}$ for the collimation angle $\theta_{c} / \theta_{\gamma}=0.3$ (upper), 0.5(middle), 1 (down) lines

For estimation the energy interval, in which the polarization is still sufficient for the nuclear physics experiments, the calculations of the polarization degree have been produced, as a function of the CB peak energy for the above values of the collimation angle. Results are shown in Fig.4.

One can see that at energy $E_{\gamma, p} \approx 10 \mathrm{MeV}$ the polarization can achieve high value, $P_{\gamma, \max } \approx 60 \%$, but at the strong collimation of the beam, $\theta_{c} \sim 0.3 \theta_{\gamma}$. At the collimation angle increasing up to $\theta_{c} \sim \theta_{\gamma}$ the polarization falls to $P_{\gamma, \max } \approx 22 \%$.

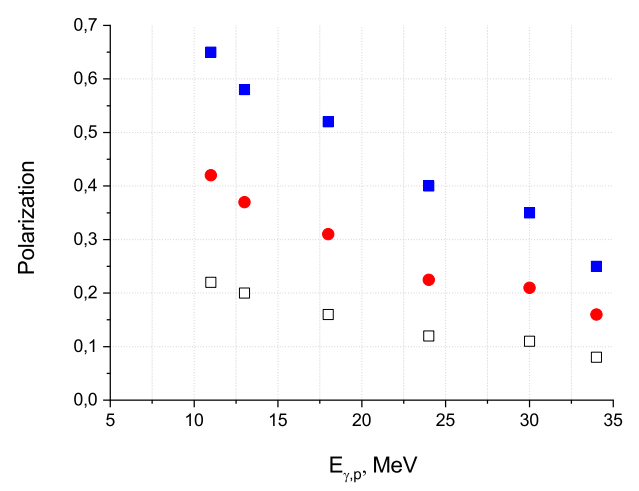

Fig.4. Polarization of the photon beam in the $C B$ maximum, $P_{\gamma, \max }$, as a function of the $C B$ peak energy for the collimation angles $\theta_{c} / \theta_{\gamma}=0.25$ (squares), 0.5 (circles), 1 (empty squaews). Electron energy is $E_{0}=100 \mathrm{MeV}$, the diamond crystal is of $0.1 \mathrm{~mm}$ thick

Experience shows that the using of the $\mathrm{CB}$ beam in the experimental researches expedient, if the polarization of the radiation is $P_{\gamma, \max }>20 \%$. Therefore, it is necessary to use the collimation of the photon beam. At that, the collimation angle should be about $\theta_{c} \sim 0.3 \ldots 0.5 \theta_{\gamma}$, as shown in Fig.4. Thus, the calculations have shown that expected parameters of the accelerator allow one to create at the LUE-300 complex the linearly polarized CB beam, which can be used for the nuclear physics researches in the energy inter- val from the reaction threshold to $E_{\gamma} \approx 35 \ldots 40 \mathrm{MeV}$.

Table 2. Parameters of the electron beam used in the calculations

\begin{tabular}{|c|c|}
\hline Maximal energy & $100 \mathrm{MeV}$ \\
\hline Energy width & $1 \mathrm{MeV}$ \\
\hline Crystal thikness & $0.1 \mathrm{~mm}$ \\
\hline Horizontal beam size & $4 \mathrm{~mm}$ \\
\hline Vertical beam size & $4 \mathrm{~mm}$ \\
\hline Horizontal divergence & $0.6 \mathrm{mrad}$ \\
\hline Vertical divergence & $0.6 \mathrm{mrad}$ \\
\hline
\end{tabular}

\section{CONTROL SYSTEM OF THE CB PARAMETERS}

For control the CB beam spectra stability during the measurements, it is planned to apply method of the Compton scattering. In addition, this technique can be used for measuring the radiation spectra of other processes, resulted from the electron interaction with any crystals. This method was realized on the Kharkov linac LUE-2000 NSC KhIPT [4, 5], for measuring spectra of the gamma-radiation produced by electron with energy $\sim 1 \mathrm{GeV}$ in crystals. The possibility to apply this method at lower electron energies about one hundred $\mathrm{MeV}$ (which will be used in the complex), has been analyzed in STCU project [6] and one can take these results for estimation to apply this method in our case.

The principle scheme of the Compton channel was shown in Fig.2 and briefly was discussed the above.

The important characteristic of the channel is the energy spread at the registration of the scattered photons, because it results to uncertainty of determination of the initial photon energy at the reconstruction the primary photon spectra from the measured one. The main source of the spread is the dispersion of the scattering photon angles due to the channel geometry. The estimation of the energy spread has been performed for geometry, shown in Fig.5. 


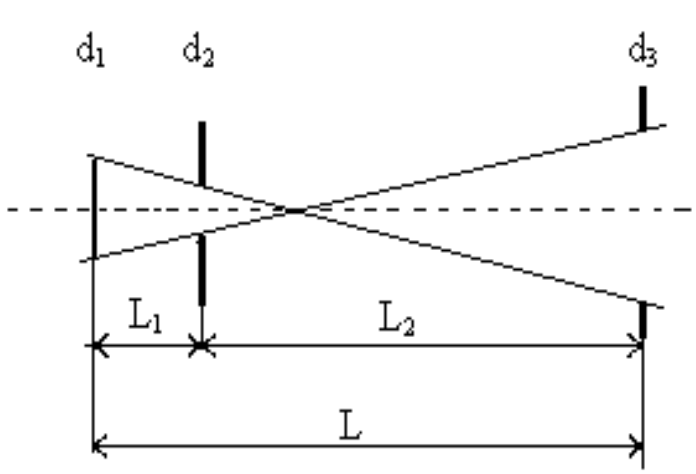

Fig.5. Scheme of the channel: $d 1$ - diameter of the target-scatterer; d2 - diameter of the first collimator; 13 - diameter of the second collimator; L1 - the distance from the scatterer to beginning of first collimator; L2 - the distance between collimators; $L$ - distance from the scatterer to end of the second collimator

Results of the calculation of the energy spread $\Delta \omega_{\gamma}$ and $\Delta \omega_{\gamma} / \omega_{c}\left(\omega_{c}\right.$ - energy of the scattered photon with initial energy $\omega_{1}=70 \mathrm{MeV}$ ) are shown in Fig.6, as a function of initial photon energy $\omega_{1}$ or scattered photon energy. The calculations demonstrate that for initial photon energy $\omega_{1}=100 \mathrm{MeV}$, the scattered photons energy is no more $60 \mathrm{MeV}$. For operation energy range being in experiments with polarized photons $E_{\gamma}, \sim 50 \mathrm{MeV}$ the scattered photon energy will be no more $E_{\gamma}<35 \mathrm{MeV}$, thus the energy spread value can be no more $\Delta \omega_{\gamma} \sim 2 \mathrm{MeV}$. In this case the energy spread of the initial gamma quanta in the restored spectrum will be no more $\Delta \omega_{\gamma} \sim 5 \mathrm{MeV}$, Fig.7, and it can be improved about twice if to increase the distance from the scatterer to the second collimator up to $L=5 \mathrm{~m}$.

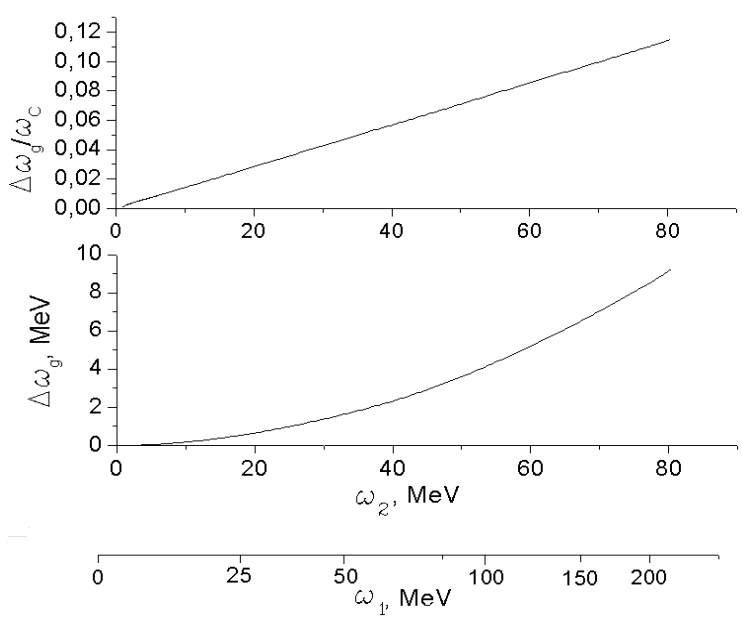

Fig.6. Relative and absolute photon energy spread for the channel characteristics: $d_{1}=10 \mathrm{~mm}, d_{2}=5 \mathrm{~mm}, d_{3}=20 \mathrm{~mm}$, $L_{1}=300 \mathrm{~mm}, L_{2}=1500 \mathrm{~mm}, L=1800 \mathrm{~mm}\left(\omega_{1}\right.$ is axis of the initial photon energy)
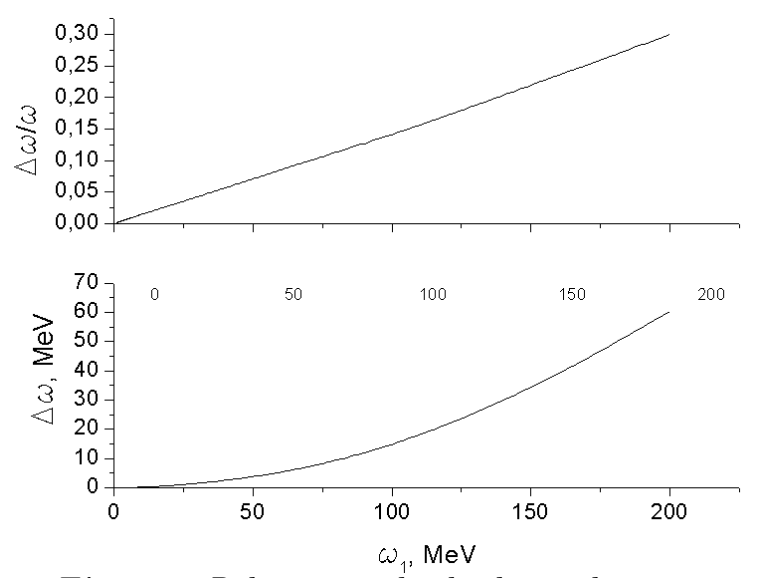

Fig.7. Relative and absolute photon energy spread of the initial gamma quanta in the restored spectrum for channel characteristics: $d_{1}=20 \mathrm{~mm}, d_{2}=5 \mathrm{~mm}, d_{3}=20 \mathrm{~mm}$, $L_{1}=900 \mathrm{~mm}, L_{2}=1500 \mathrm{~mm}, L=2400 \mathrm{~mm}$

\subsection{ESTIMATION OF THE COHERENT BREMSSTRAHLUNG SPECTRA CONTROL EFFICIENCY}

For estimation of the CB beam control system work, the mathematical model of the channel has been developed on the base of GEANT-3 package and simulation was executed. At the simulation, as the primary photon spectrum, the real spectrum, obtained at MAX-lab facility was used. The maximal energy of the spectrum was $144 \mathrm{MeV}$, but energy interval up to $60 \mathrm{MeV}$ was taken into simulation procedure, Fig.8. The CB beam was scattered on the targets from carbon 2, 5, and $10 \mathrm{~mm}$ thick. Diameter of the photon beam on the target was $1 \mathrm{~cm}$, it distribution over target square was equilibrium. The channel axis was directed under angle $5^{0}$ to the beam axis, the angular acceptance of the channel was chosen $\pm 0.23^{0}$. The collimators position and their sizes were taken in accordance with values presented in Fig.6. The scattered photons were detected by a $\mathrm{NaI}$ detector $9 \mathrm{~cm}$ diameter and $30 \mathrm{~cm}$ thick.

Simulation result of the photon spectrum scattered on the target $5 \mathrm{~mm}$ thick is presented in Fig.8. The upper bound of the scattered photon spectra is $\sim 45 \mathrm{MeV}$. The part of scattered photons detected by $\mathrm{NaI}$ detector for this scatterer is $\sim 10^{-4}$. The detected photon spectrum was converted in digital form and was processed by the program of spectra reconstruction. The results were presented in Fig.9.

As a whole, the primary and reconstructed photon spectra are in a good agreement at region of the CB maximum and some worse at higher energies that is a result of the experimental data errors and statistical fluctuations of the measured photon spectrum. Therefore increasing of the data statistical accuracy is necessary up to level of the data at the CB peak range. 

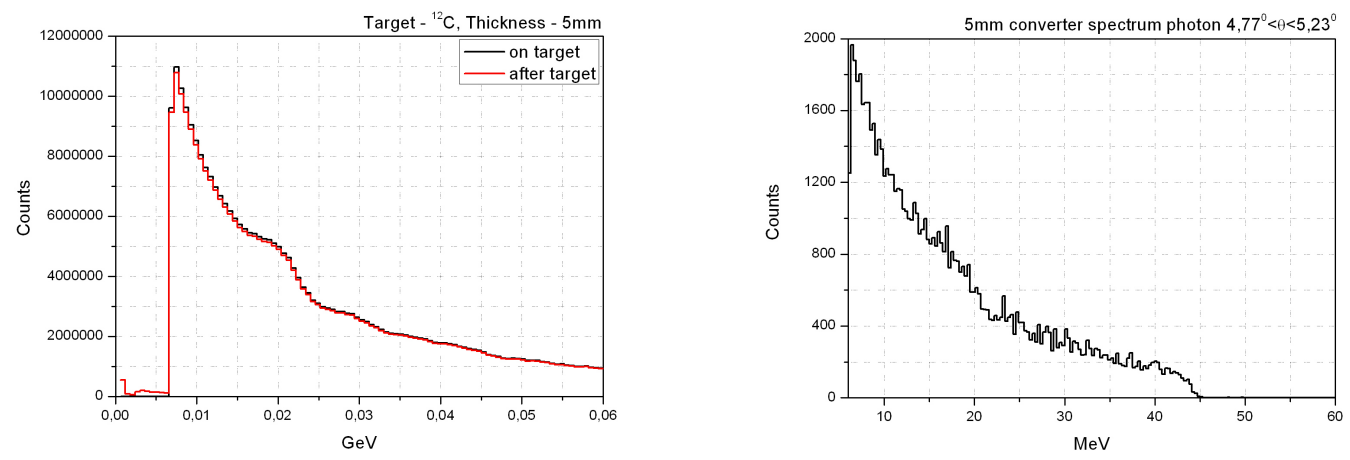

Fig.8. The primary photon spectra that hit the ${ }^{12} \mathrm{C}$ scatterer with thickness $5 \mathrm{~mm}$ (left) and scattered photon spectrum (right) detected by NaI detector after passing the measuring channel of the control system

At the above characteristics of the channel and $1 \mathrm{~cm}$ target thickness, the necessary statistics will be obtained during $30 \mathrm{~min}$ at the photon beam intensity $10^{7} \mathrm{\gamma} / \mathrm{s}$. Reducing intensity of the beam, that passes a target, and its spectrum is not significant for thicknesses $<5 \mathrm{~mm}$. Some decreasing is observed at target thickness $10 \mathrm{~mm}$. The simulation has shown the system on the base of the Compton scattering can control the CB beam parameters by controlling the $\mathrm{CB}$ beam peak position and its coherent effect value.

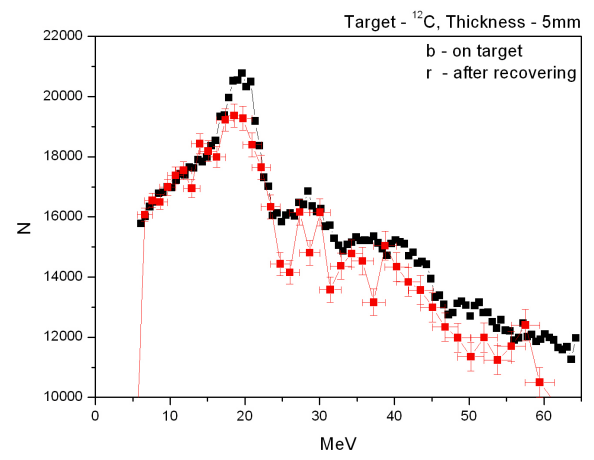

Fig.9. The primary (black) and reconstructed (red) relative $D / A l C B$ spectrum

\section{BEAMS OF ELECTRONS AND POSITRONS OF LOW INTENSITY}

Possibility of creating the beams of secondary particles (electrons and positrons) of low intensity (1 particle per accelerator pulse) was considered in $[8,9]$. It was assumed to use the parallel transfer of the electron beam on the exit of the LUE-300 accelerator. These beams are formed from electrons and positrons, which are obtained due to interaction of the primary electron (or photon) beam with a heavy metal converter. The production of electron-positron pairs is an electrodynamic process, in which particles of the pair are predominantly produced at a small angle (several degrees in our conditions) relatively to momentum of the gamma-quanta. Multiple scattering in the material of the converter greatly affects the particle angular distribution. Using the converter of a pencil shape may reduce the multiple scattering of the particles in the converter material and allows one to get narrower angular distribution of the emitted particles [8]. The particles emitted from the convertor are captured by the dipole magnet into beam line No.2, where they are formed, and sent to the experimental hall, as shown in Fig.2.

The energy and angular distributions of the secondary particles, which can be obtained at the interaction of the electron (or photon) beam with maximal energy of $100 \mathrm{MeV}$ with various targets, were studied by simulation, using the GEANT-4 package $[9,10]$. Obtained results can be used for the preliminary estimation in our case.

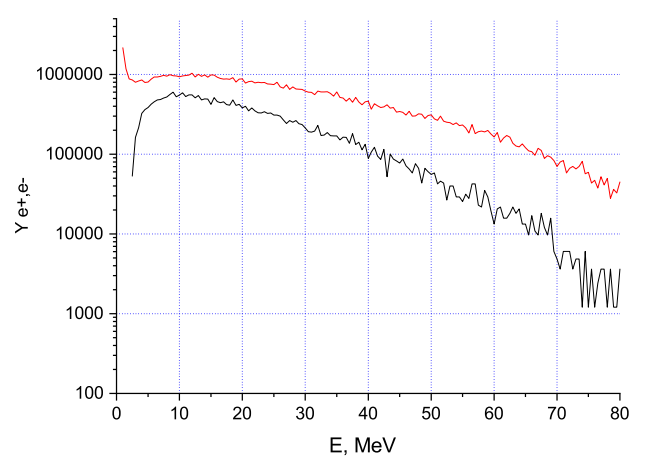

Fig.10. Energy distribution of $e^{-}$(red line) and $e^{+}$(black), produced at interaction of $E_{0}=100 \mathrm{MeV}$ electron beam with tungsten converter of $d=3.6 \mathrm{~mm}$ in diameter and $L=7 \mathrm{~mm}$ thick, captured in the beam line with an angular acceptance of $\Delta \theta=10-20^{\circ}$. The particle yield is normalized to an electron current of $0.1 \mathrm{nA}$

The calculations have shown, the most optimal for the secondary particles production are the tungsten converters. Fig.10 shows the results of simulation the number of electrons and positrons, produced at the interaction of the $E_{0}=100 \mathrm{MeV}$ electron beam with a tungsten cylinder converter, of $L=7 \mathrm{~mm}$ length $\left(\sim 2 X_{0}\right)$ and of $d=3.6 \mathrm{~mm}$ in diameter, and which are captured into the beam line with an angular acceptance of $\Delta \theta=10 \ldots 20^{\circ}$.

One can see that at the electron current of $1 \mu A$, 
the expected number of the particles with energy $(\sim 50 \pm 0.5) \mathrm{MeV}$, accepted into the beam line, will be $\sim 10^{9}$ per second.

The number of accepted particles should be corrected for the apertures of the following collimators and the transport system efficiency. According to approximate estimates, this factor should not exceed $10^{-7} \ldots 10^{-8}$. Then at the electron beam current of $1 \mu A$, the yield of secondary particles will be sufficient to obtain a beam of electrons or positrons with an intensity of $\sim 1 \ldots 100$ particle per accelerator pulse in the energy range of $10 \ldots 80 \mathrm{MeV}$ with an energy resolution of $\sim 1 \mathrm{MeV}$. The expected angular divergence should be no more $1 \mathrm{mrad}$. That will be less than the critical angle of the axial channeling. For particles with energy of $60 \mathrm{MeV}$, this angle is $\sim 1.9 \mathrm{mrad}$ for the silicon and $\sim 1.3 \mathrm{mrad}$ for the diamond crystals.

\section{POSSIBLE RESEARCH DIRECTIONS}

In the case of the project realization, there are wide opportunities for implementing a wide range of research programs in the field of studying the interaction of radiation with amorphous and crystalline matter, nuclear physics and astrophysics, as well as in applied research.

\subsection{STUDIES OF THE INTERACTION OF ELECTRONS AND POSITRONS WITH AMORPHOUS MATTER AND CRYSTALLINE STRUCTURES}

These studies can be carried out on both beam lines: on line-1 with high intensity electron beam, and on the line No. 2 with electron and positron beams of low intensity. We briefly outline the main directions of the possible investigations, see [11] for more details.

- Investigation of the angular distributions of relativistic electrons and positrons scattered by crystals, depending on the thickness of the crystal, its structure and orientation relative to the incident beam at the particle energies up to $100 \mathrm{MeV}$ energies of the order.

- Study of characteristics of the coherent radiation produced by the electrons and positrons with energies of the $10 \ldots 80 \mathrm{MeV}$ in the crystals at axial and plane orientations under conditions when there is phenomenon of dynamic chaos in the particles movement. Comparison of the characteristics of the coherent radiation produced by relativistic electrons and positrons.

- Study of the characteristics of parametric x-ray radiation of relativistic electrons in a crystal. Based on this process, it is possible to create Xray sources with very narrow lines in the spectral distribution of radiation. Studying the factors leading to broadening of these lines (crystal thickness, multiple scattering, photon absorption, etc.).
- Study of transition radiation in stacks of plates and in layered media. Such study is relevant, because on the basis of this process it is possible to create easily tunable sources of hard electromagnetic radiation.

- Measurement of the electron emission from amorphous and crystalline targets. Investigation of the orientation dependences of the deltaelectron's yield, when the beam passes through a crystal. Analysis of the yield of the deltaelectrons in the direction of the incident beam and in the opposite direction will make it possible to estimate the lengths of the dechanneling of particles.

- Measurement of ionization losses of electrons in thin targets.

- Investigation of the effects of dynamic diffraction in coherent X-rays in single-crystal targets in Laue and Bragg geometry. Investigation of the influence of boundary conditions on the intensity of the parametric X-rays.

- Investigation of spectral characteristics and the radiation mechanisms of the electrons and positrons in thin crystals.

\subsection{INVESTIGATION OF THE STRUCTURE OF NUCLEI AND MECHANISMS OF PHOTONUCLEAR REACTIONS}

- Investigation of two-body photodisintegration of light nuclei $\left({ }^{6} \mathrm{Li},{ }^{7} \mathrm{Li},{ }^{9} \mathrm{Be}\right)$ by bremsstrahlung and linearly polarized photons.

- Investigation of nuclear fission by bremsstrahlung and linearly polarized photons and electrons.

- Measurement with high accuracy of elastic scattering of electrons on protons and atomic nuclei at very small transferred momenta. Determination of electric radius of the proton and nuclei.

- Study of the nuclear reactions (e.g., pprocesses), which give contribution to production of elements in the Universe.

\subsection{APPLIED RESEARCH}

These researches can be performed on the beams of the electrons and positrons of low intensity on the line No.2.

- Detector testing.

- Study of characteristics of the scintillation materials. 


\section{CONCLUSIONS}

The main goal of the proposed project is to resume experimental research at IHEPNP. In order to speed up this process, at the first stage it is supposed to use the existing and still functioning equipment,and to make its modernization, in order to improve the beam parameters and make the facility more or less competitive. It is planned, firsly, to increase the beam energy to $100 \mathrm{MeV}$, and secondly, to create two beam lines to expand the experimental possibilities of the facility. The one beam line will be aimed on experiments with high intensity beams of the electron and photons, including the linearly polarized, the other beam line will be aimed on experiments with low intensity beams of the electron and positrons, $\sim 1 \ldots 10$ particles per impulse of the accelerator.

The commissioning of these beam lines, with the planned beam parameters, will open up opportunities for the implementation of the research programs in the field of interaction of the radiation with amorphous and crystalline matter, nuclear physics and astrophysics, as well as in applied research.

Firstly, unique opportunities will be provided for studying the interaction of electrons and positrons with amorphous matter, crystals and nanostructures. The facility provides measurement of the gammaradiation produced by the electrons and positrons in the crystals in the wide range of the crystals thicknesses, and its comparative analysis. The radiation measurements can be supplemented by measuring of the electron's and positron's scattering in the crystal at the same experimental conditions. That will allow one to determine the particles dynamics in the crystal and the radiation mechanisms.

Secondly, it becomes possible to study the cluster structure of light nuclei in the energy riange from the reaction threshold threshold, including the region of giant dipole resonance, using the beams of the linearly polarized photons. Until now, such studies have practically not been carried out.

Studying the characteristics of scintillation materials and testing detectors are areas of research that may also be in demand in connection with the creation of new experimental facilities in the future.

\section{References}

1. Yu.M. Ranyuk. Laboratory No.1. Nuclear physics in Ukraine. Kharkiv: Akta, 2001, 589 p.

2. V.Androsov et al. The start of X-ray generator NESTOR commissioning // PAST. 2013, N6(88), p.20-23.

3. F.A. Natter et al. Monte Carlo simulation and analytical calculation of coherent bremsstrahlung and its polarization // Nucl. Instr. and Meth. B211. 2003, p.465-486.

4. B.I. Shramenko et al. // Pisma v ZTF. 1978, v.4, N23, p.1423 (in Russian).

5. V.I. Vit'ko et al.// Problems of Atomic Science and Technology. Series "Methods of Physics Experiment". 1980, v.2(6), p.43.

6. STCU project 3239. Technical report T02. 2007

7. V.P. Lapko, N.F.Shul'ga, A.S. Esaulov. Efficiency of positron source versus shape of target // Phys. Lett. 2006, v.359A, p.8.

8. V.B. Ganenko, D.D. Burdeinyi and others. Fundamental and applied advances in nuclear physics for the needs of medicine, national government, ecology. Stage 3. Model of generation of electrons and positrons in a converter from a beam of electrons with an energy of $100 \mathrm{MeV}$. Promizhnyy zvit about NDR on the topic III-211 (IFVEYAF). Kharkov, 2012, 32 p.

9. V.B. Ganenko, D.D. Burdeinyi, V.M. Khvastunov et al. Fundamental and applied advances in nuclear physics for the needs of medicine, national government, ecology. Stage 6. Development of the diagram of the beam line, propositions of the elements. Promizhnyy zvit about NDR on the topic III-2-11 (IFVEYAF). Kharkov, 2013, 32 p.

10. A.Yu. Buki, V.B. Ganenko, A.Yu. Korchin, V.V.Kotlyar, N.I.Maslov and V.I. Truten, S.P. Fomin, A.V.Shebeko, N.G. Shevchenko, N.F. Shul'ga. Fundamental and applied research on a linear accelerator-recirculator of electrons with energies up to $730 \mathrm{MeV}$ (SALO project) / Monographic review, 116 p., NSC KIPT, Kharkov, 2006. 


\title{
ЭКСПЕРИМЕНТАЛЬНАЯ УСТАНОВКА ИФВЭЯФ ДЛЯ ФУНДАМЕНТАЛЬНЫХ И ПРИКЛАДНЫХ ИССЛЕДОВАНИЙ В ОБЛАСТИ ЭНЕРГИЙ ДО 100 МэВ
}

\author{
В. Б. Ганенко, В. И. Касилов, Г. Д. Коваленко, Н. И. Маслов, И. Л. Семисалов
}

Обсуждается возможность создания экспериментальной установки в здании №3 ИФВЭЯФ ННЦ ХФТИ (ускорительный комплекс ЛУЭ-300) на основе имеющегося ускорителя электронов ЛУЭ-60 и существующей экспериментальной инфраструктуры. Планируется увеличить энергию электронного пучка до $100 \mathrm{MэВ} \mathrm{и} \mathrm{создать} \mathrm{две} \mathrm{пучковые} \mathrm{линии:} \mathrm{одну} \mathrm{для} \mathrm{исследований} \mathrm{с} \mathrm{интенсивными} \mathrm{пучками} \mathrm{электронов} \mathrm{и}$ фотонов, в том числе линейно поляризованных, а другую - для исследований с пучками электронов и позитронов низкой интенсивности. Реализация проекта откроет возможности для выполнения исследовательских программ в области взаимодействия излучения с аморфным веществом и кристаллами, в области ядерной физики и астрофизики, а также прикладных исследований.

\section{ЕКСПЕРИМЕНТАЛЬНА УСТАНОВКА ІФВЕЯФ ДЛЯ ФУНДАМЕНТАЛЬНИХ І ПРИКЛАДНИХ ДОСЛІДЖЕНЬ В ОБЛАСТІ ЕНЕРГІЙ ДО $100 \mathrm{MeВ}$}

\author{
В. Б. Ганенко, В. Й. Касілов, Г. Д. Коваленко, М. І. Маслов, І. Л. Семісалов
}

Обговорюється можливість створення експериментальної установки в будівлі №3 ІФВЕЯФ ННЦ ХФТІ (прискорювальний комплекс ЛУЕ-300) на основі чинного прискорювача електронів ЛУЕ-60 і існуючої експериментальної інфраструктури. Планується збільшити енергію електронного пучка до $100 \mathrm{MeB} \mathrm{i}$ створити дві пучкові лінії: одну для досліджень з інтенсивними пучками електронів і фотонів, у тому числі лінійно поляризованих, а іншу - для досліджень з пучками електронів і позитронів низької інтенсивності. Реалізація проекту відкриє можливості для виконання дослідницьких програм в області взаємодії випромінювання з аморфною речовиною і кристалами, в галузі ядерної фізики і астрофізики, а також прикладних досліджень. 